\title{
Claves del existencialismo en la novela En vida de Haroldo Conti
}

\author{
Youssouph COLY \\ Universidad Complutense de Madrid
}

\begin{abstract}
RESUMEN
La escritura de En vida se inscribe en el marco de una literatura argentina de los años 60 y 70 caracterizada por la narrativización de los conflictos del individuo con su espacio vital y la sociedad moderna en su globalidad. Una orientación debida en parte a la influencia del "Nouveau Roman" francés y del existencialismo de Heidegger, Sartre y Camus. Este artículo analiza precisamente las principales claves de este sistema de pensamiento dentro de la novela de Haroldo Conti.
\end{abstract}

Palabras clave: Haroldo Conti, En vida, existencialismo.

\section{Existentialism keys in Haroldo Conti’s novel named En vida}

\begin{abstract}
The writing of En vida lies within the scope of an argentinian literature of the Sixties and Seventies characterized by the narrativization of the conflicts of the individual with his vital space and the modern society in its entirety. An orientation due partly to the influence of the French 'Nouveau Roman' and the existentialism of Heidegger, Sartre and Camus. This article precisely analyzes the presence of the main keys of this system of thought in the Haroldo Conti's novel.
\end{abstract}

Keywords: Haroldo Conti, En vida, Existentialism.

SUMARIO: I.Consideraciones preliminares. I.1.Sobre el autor. I.2.Argentina y el existencialismo. II.La angustia. III.La existencia inauténtica. IV.La búsqueda de autenticidad.

\section{CONSIDERACIONES PRELIMINARES}

\section{I.1. Sobre el autor}

Haroldo Conti nace el 25 de mayo de 1925 en el pueblo de Chacabuco (provincia de Buenos Aires). Su narrativa empieza y se desarrolla entre las décadas de los sesenta y los setenta; un período de la historia argentina marcado por graves crisis políticas y socio-económicas, pero también por el boom de la narrativa tanto en América Latina. Muy pronto, Conti se posicionará como una de las figuras más 
relevantes de las letras argentinas, cosechando numerosos premios, antes de ser secuestrado y torturado a muerte por las fuerzas de seguridad del dictador Jorge Rafael Videla en 1976. Es autor de cuatro novelas: Sudeste (1962), Alrededor de la jaula (1966), En vida (1971) y Mascaró, el cazador americano (1975). También escribe cuentos, que publica en los libros Todos los veranos (1964), Con otra gente (1967) y La balada del álamo carolina (1975), y en numerosas revistas literarias.

La narrativa de Conti, por la fuerte carga subjetiva del lenguaje y por su orientación hacia los marginales, tiene un contenido ideológico y se yergue como respuesta a las vicisitudes de la sociedad en un período de la historia argentina lleno de sobresaltos y desajustes. Recorre todos sus relatos una visión dialéctica de la realidad argentina, por más que los diferentes narradores se guarden de emitir juicios sobre los acontecimientos relatados o la actitud de los protagonistas. Los textos contianos son, desde este punto de vista, tendenciosos, revolucionarios, ya que, como sostiene Lukacs, "la verdadera reproducción dialéctica y estructuración literaria de la realidad presupone el partidismo del escritor" (Lukacs, 1966: 114). Descansan todos en una crítica implícita de la hegemonía de poderes extraños al ser individual y de la dictadura de la moral capitalista. Sus líneas se tiñen de una añoranza bucólica de corte virgiliano o pavesiano. El pueblo y la periferia están omnipresentes en todos los relatos y en la mente de los protagonistas; y ese sentimiento de añoranza da fe de los problemas de adaptabilidad de los provincianos en la gran metrópoli. Además, Conti ha sabido mantener un diálogo dramático entre el abandono de ciertos espacios y su belleza, entre el sufrimiento de los hombres marginados y su alegría de vivir. Entre sus grandes méritos está el conseguir poetizar e idealizar lo marginal, lo periférico, la miseria, la exclusión, las frustraciones, la delincuencia. La novelización de esa saga de personajes marginales y frustrados característicos del existencialismo sartreano o camusiano, cuyos proyectos y propósitos acaban casi siempre en una desilusión y un fracaso, se inscribe en la dinámica de exposición -a veces tendenciosa- del cúmulo de frustraciones, del ambiente de ruina, destrucción y crisis emocional de las décadas posteriores a la Gran Guerra. Ese profundo humanismo, ese fuerte compromiso con la vida y la libertad es, en gran medida, lo que confiere a las narraciones de Conti una singularidad y un atractivo que trascienden fronteras y mantienen su actualidad a pesar de los años.

La novela que analizamos, En vida ${ }^{l}$, es, en muchos aspectos, donde más se materializa la narrativización de la inadaptabilidad del individuo en la sociedad moderna y capitalista. Aquí Conti noveliza la angustia, la abulia de los inadaptados de la ciudad, de la gente que vive y pervive como marginados en los centros urbanos, víctimas del abigarrado progreso de la segunda mitad del Siglo Veinte. Oreste, el

${ }^{1}$ En este artículo, trabajaremos exclusivamente con la edición de 1971 de Barral Editores de Barcelona. Las citas aparecerán con el número de la página o las páginas correspondientes entre paréntesis. 
protagonista principal, es un pequeño funcionario insatisfecho con la vida que lleva en una Buenos Aires antropófaga, devoradora de personalidad, individualidad, dignidad y aspiraciones. Para él, la única salida es la huida hacia tierras más favorables, tierras donde las fantasías y vivencias de la infancia resurjan y se actualicen a la par que se materialicen los fantasmas de sus sueños. Es más: las inquietudes originadas por su sentimiento de desgarro emocional y desarraigo existencial provocan sus deseos de liberación y su inestabilidad física y psíquica. Por todos estos aspectos, se ve claramente que un análisis de las claves existencialistas de esta novela se impone.

\section{I.2. Argentina y el existencialismo}

Si bien es cierto que el existencialismo hace su entrada y marca su influencia en Argentina a partir de la difusión de los textos de Sartre y Camus, no es menos cierto que este país siempre se ha mostrado abierto a la filosofía de la existencia ${ }^{2}$. Pues, el país ya se había familiarizado más o menos con el pensamiento alemán -en su mayoría heideggeriano- sobre el Ser, la existencia y la trascendencia. ${ }^{3}$ Carlos Astrada, quien había tenido el privilegio de asistir a cursos dictados por, entre otros profesores, Max Scheler, Edmund Husserl y el propio Martin Heidegger (Mingorance, 1996: 183), publica, en 1933 ya, El juego existencial y, en 1936, Idealismo fenomenológico y metafísica existencial. También escribe poco después El juego metafísico (1942) y La revolución existencial (1952). Fiel a las enseñanzas de Heidegger, el profesor Astrada reivindica "el tomar como punto de partida de toda reflexión filosófica la desnuda facticidad de la existencia humana (dasein), expresada en su estar-en-el-mundo" (ibíd.: 185). Otro pensador argentino, Miguel Angel Virasorio, plantea en su libro, La libertad, la existencia y el ser (1942), el problema de la dialecticidad del existencialismo. Virasorio parte del principio según el cual el Ser es inherente a todo Dasein, para desembocar en que la libertad, en cuanto proyecto absoluto de toda existencia, consiste en realizarse plenamente (ibíd.: 185). El profesor Nicolás Derisi, filósofo de formación tomista, publica, entre otros libros, Filosofia moderna y filosofia tomista (1945) y Tratado de Existencialismo y Tomismo (1956). En ambos libros, estudia las relaciones entre el pensamiento católico fiel a

${ }^{2}$ No caeremos en el largo debate que consiste en intentar diferenciar el existencialismo de la filosofía de la existencia. Utilizaremos indistintamente los dos términos para referirnos al sistema de pensamiento metafísico que toma la "existencia" como eje central de su reflexión. Así, nos salvaremos de las clasificaciones categoriales que tienden a desvincular a Heidegger de los existencialistas. Clasificaciones que, por otra parte, siguen al propio pensador alemán, quien también declara no ser un filósofo existencialista.

${ }^{3}$ Eso se debe a que, en palabras de José Luis Romero, "Francisco Romero desde el país, y Carlos Astrada, Saúl A. Taborda y Juan Luis Guerrero en las aulas de las universidades alemanas, se familiarizaron con el nuevo pensamiento alemán y comenzaron a difundirlo en las páginas de las revistas y, más tarde en la cátedra..." (Romero, 1965: 173-174) 
los postulados de Santo Tomás de Aquino y la filosofía existencialista (ibídem: 187). Lo más interesante de los trabajos de Derisi es el saber sistematizar con acierto la nueva filosofía, en tanto que señala ya que el existencialismo constituye un redescubrimiento de la finitud, la contingencia y el desamparo propios a la existencia humana (ibíd.: 187).

Vista así la vigencia de la filosofía de la existencia dentro del universo intelectual argentino, no es de extrañar el fervoroso entusiasmo con el que se recibe el existencialismo de Jean-Paul Sartre después de la Segunda Guerra Mundial. Pero, aunque es absolutamente innegable que el pensamiento filosófico, tanto de Heidegger como de Sartre, forja la actitud de gran parte de los intelectuales de la generación posterior a 1945, son sus versiones literarias las que más atraen las pasiones y adhesiones (Romero, 1965: 178-179), hasta tal punto que Susana Tasca sentencia que nadie en la Argentina de los años 50 podía escapar del existencialismo, sobre todo después de 1955 (Speroni-Posada, 2000: 569)

En el ámbito filosófico, el existencialismo nace como una poderosa reacción contra el olvido del Ser en la filosofía occidental desde Platón hasta Hegel ${ }^{4}$ y contra lo que Pedro Fontán-Jubero llama acertadamente el "proceso de despersonalización" filosófica, al ver que estos sistemas filosóficos conducen a "la total pérdida del hombre, a la negación completa de su singular interioridad, de sus anhelos y angustias específicas, de sus tareas y proyectos existenciales" (Fontán-Jubero, 1991: 19). El proceso de despersonalización en el plano filosófico se acompaña de otro, en el plano sociopolítico. El nacimiento de totalitarismos (fascismo y comunismo) en la primera mitad del siglo XX conduce a excesos que tienen como nombres: funcionalización del hombre y degradación de las libertades individuales en beneficio de susodichos intereses colectivos. A ello se suman las dos guerras mundiales que dibujan en el mundo un apocalíptico cuadro de ruinas, muerte y desolación. Frente a esta situación sociopolítica, decíamos, nace una crisis de conciencia que desemboca en una reflexión sobre el sentido -o el sinsentido - de la existencia humana.

Mientras que, como apuntábamos, el pensamiento ilustrado tiende a universalizar al hombre, proclamando al mismo tiempo el poder ilimitado de la razón, el existencialismo, él, rechaza este "panlogismo hegeliano" (ibíd.: 26) y se centra en el estudio del individuo, no como un dato objetivo sino como una existencia, un proyecto, un asunto. Para el existencialismo, el "hombre en general" no existe. La exis-

${ }^{4}$ La metafísica realista de Platón, Aristóteles o Santo Tomás de Aquino, de vocación supuestamente esencialista, no se interroga en realidad sobre el Ser sino sobre el Ente. En la metafísica idealista, Kant, Fichte, Schelling y, sobre todo, Hegel, ponen el acento sobre la razón del sujeto. Para ellos, la razón subjetiva es el pilar fundamental de la interpretación del ente. $\mathrm{Y}$ el positivismo cientificista subjetiviza al Ser interpretándolo como Ente o como instrumento. 
tencia no puede objetivarse en tanto que el concepto de "ser humano" es una abstracción que conduce a una despersonalización del existente (Fullat, 2002: 80).

Hay que dejar claro también que si los existencialistas se abrevan ideológicamente en el pensamiento de Sören Kierkegaard ${ }^{5}$ y Friedrich Nietzsche ${ }^{6}$, de Edmund Husserl cogen el método de análisis fenomenológico. ${ }^{7}$ Es, pues, sobre la base de este método que se lanzan a la descripción de los fenómenos del Ser y la existencia la gran mayoría de los filósofos existencialistas, a los que Jean-Paul Sartre clasifica en cristianos -como Karl Jaspers, Gabriel Marcel- y ateos -como Heidegger y él mismo- (Sartre, 1999: 27). El existencialista francés insiste en que, a pesar de esta diferencia entre las dos clases de existencialismos, ambas escuelas coinciden en que la existencia precede a la esencia (id).

En todo caso, dado que Heidegger y Sartre son los existencialistas que mayor impacto producen en los sectores intelectuales argentinos, en general, y en Conti, en particular -cosa que demostraremos luego -, nuestro análisis del existencialismo se centrará en las propuestas de estos filósofos, cuyos principales libros, El ser y el tiempo (1927) y El ser y la nada (1943), respectivamente, encierran toda su ontología del Ser y el existente relacionada con su mundanidad, la soledad, la angustia, la libertad, la autenticidad o la "inautenticidad".

Tal como lo concibe el existencialista, el hombre empieza por existir, por encontrarse en el mundo antes de definirse. Heidegger consagra la primera sección de $E l$ ser y el tiempo en demostrar la mundanidad del Ser (Heidegger, 1996: 53-252). Para él, el Dasein, el "ser-ahí", es un "ser-en-el-mundo". Al encontrarse arrojado en el mundo, no vive aislado por la sencilla razón de que es, precisamente por su mundanidad, un "ser-con". El ente se pone en relación con otros Dasein, que, al mismo tiempo que forman su mundo, lo comparten con él. En el mismo libro, el existencialista alemán insiste en la temporalidad del Ser (ibíd.: 253 y ss.). Para él, el

${ }^{5}$ El teólogo danés es considerado como el precursor del existencialismo del siglo XX en tanto que su filosofía, centrada en la existencia, subraya con nitidez la singularidad de la existencia de cada individuo en su situación vital. En sus libros de mayor resonancia, Temor y temblor (1843) y El Concepto de la angustia (1844), Kierkegaard declara, con un planteamiento religioso, que no hay existencia sin ser humano y que la existencia es la del existente individual. Por tanto, siempre según él, la atención del filósofo ha de centrarse en el existente.

${ }^{6}$ Ya en Más allá del bien y del mal el creador del Vitalismo destaca la primacía de la vida individual sobre su racionalización y rechaza cualquier intento de encasillamiento reductivo del hombre bajo los supuestos del Bien, el Mal, la Moral social o religiosa, la Verdad.

${ }^{7}$ Según Pedro Fontán-Jubero, "El método fenomenológico rehusaba encerrarse en presupuestos abstractos, y encaminaba su esfuerzo filosófico en describir exactamente los fenómenos tales como aparecen a la conciencia. No autorizaba, para el estudio del hecho concreto, deducción ni interpretación alguna; la filosofía debía limitarse a describir lo inmediato." (Fontán-Jubero, 1991: 34). 
Dasein es a la vez retorno al pasado y proyección hacia el porvenir, siendo el presente un hacerse, un "todavía no". En esta tensión entre pasado y futuro, Heidegger marca su predilección por el segundo, en tanto en cuanto que concibe el Dasein como una fuga perpetua hacia sus posibilidades. Pero "La muerte es la más peculiar posibilidad de "ser-ahí". El "ser relativamente a ella" abre al "ser ahí" su más peculiar "poder ser", aquel en el que va absolutamente el ser del "ser ahí" (ibíd.: 287). El Ser, la esencia del ser, es entonces un "ser-para-la-muerte". De ahí, la finitud del hombre. Para Heidegger, cuando el hombre se encuentra ante la nada, o sea, ante la posible imposibilidad de su existencia, cuando toma conciencia de que está destinado a la muerte, experimenta un estado de angustia. Así, afirma, "El "ser relativamente a la muerte" es en esencia angustia" (ibíd.: 290).

Sin embargo, si Heidegger considera que el Ser es más amplio en posible que en real, Jean-Paul Sartre da mayor importancia a la contingencia de éste. Para él, dado que hacemos acto de presencia en el mundo de las cosas, con todos los asedios (del cuerpo, la carne, la opresión, lo viscoso) que ello supone, el Ser es lo que es en presente. Pero, no por ello deja de coincidir con Heidegger en que la esencia del Ser (el en-sí) es un hacerse (un para-sí). En El existencialismo es un humanismo, donde resume y aclara las propuestas avanzadas en su tratado de ontología del Ser (El ser y la nada), declara Sartre que el hombre es un hacerse un proyecto. ${ }^{8}$ Partiendo Sartre de la no existencia de Dios ni de moral alguna, considera que el hombre, en la medida en que se encuentra arrojado al mundo sin razón y sin consentimiento suyo, está condenado a asumir la responsabilidad de todo lo que hace. De hecho, el hombre es un ser totalmente libre porque, si Dios no existe, dice Sartre, "no encontramos frente a nosotros valores u órdenes que legitimen nuestra conducta" (Sartre, 1999: 43). La angustia sartreana procede precisamente de esta situación del hombre como "condenado a ser libre" en sus elecciones, y a ser responsable de las mismas. $\mathrm{Al}$ asumir su libertad, al actuar de tal o cual manera, el hombre no puede estar seguro de que obra bien o mal porque no hay principios ni valores exteriores que justifiquen sus actuaciones, siendo él el fundamento sin fundamento ( $\sin$ fin) de los valores. Se apoderan de él, entonces, angustia, desamparo y desesperación, ante su propia absurdidad, y la de sus actos.

${ }^{8}$ Para él, "el hombre empieza por existir, se encuentra, surge en el mundo, y [...] después se define. El hombre, tal como lo concibe el existencialista, si no es definible, es porque empieza por no ser nada. Sólo será después, y será tal como se haya hecho [...] El hombre es el único que no sólo es tal come él se concibe, sino tal como él se quiere, y como él se concibe después de la existencia; el hombre no es otra cosa que lo que él se hace. Éste es el primer principio del existencialismo. [...] el hombre empieza por existir, es decir, empieza por ser algo que se lanza hacia el porvenir, y que es consciente de proyectarse hacia el porvenir. El hombre es todo un proyecto que vive subjetivamente." (Sartre, 1999: 31). 
En opinión de los existencialistas, el hombre arrojado al mundo suele adoptar una actitud de indiferencia ante su contingencia (facticidad), su finitud (muerte), su falta de libertad y la angustia que nace de estas situaciones. El Ser lleva así una existencia inauténtica. En ésta, se encuentra perdido en el mundo, en la cotidianidad, y se deja llevar por el transcurso de los acontecimientos. El Ser inauténtico se confunde con la masa; huye de sus responsabilidades sin buscar realizar su verdadero Yo. Es el "hombre masa", el "se" heideggeriano, que no se compromete a "ser jamás lo que él es, oponiendo la "distracción" a las reclamaciones de una libertad" (Jolivet, 1970: 196).

Frente a la "existencia inauténtica" despersonalizadora, los existencialistas proponen la "existencia auténtica". En vez de adoptar una actitud evasiva ante la muerte, el existente auténtico toma conciencia de su finitud; asume que no es nada y que está destinado a la nada. Es sólo así cómo puede ejercer, con toda la carga de responsabilidad y angustia que ello requiere, su radical libertad. Al asumir su libertad, el ente que lleva una vida auténtica lo hace de acuerdo con su propio Ser. De este modo, se realiza como proyecto y realiza su verdadera condición de hombre.

Después de estas consideraciones preliminares, vamos a entrar de lleno en el objetivo que nos hemos trazado al principio de este artículo: el análisis de las manifestaciones en la novela contiana En vida de las claves principales del existencialismo cuyos contornos acabamos de delinear. Nos centraremos en la angustia, la existencia inauténtica y la búsqueda de la autenticidad.

\section{LA ANGUSTIA}

Conviene precisar aquí que manejaremos indistintamente los conceptos de angustia y de ansiedad. Los aprehenderemos como conceptos complementarios, para designar el estado de agitación, inquietud, aflicción, zozobra del ánimo y aprieto del ser humano ante las adversidades de la realidad circundante. Para Werner D. Frölich, la angustia puede interpretarse como una advertencia general de peligro, tanto físico como psíquico:

Esta advertencia de peligro tiene la función de preparar el estado del cuerpo, las modalidades vivenciales y la conducta para aquellos casos en los que no pueden hacer frente a las exigencias del entorno ni tampoco a las del medio "interno" que se manifiesta en forma de autorreferencia del pensamiento. (Frölich, 1986: IX)

El problema de la angustia como generadora de pulsión y motivación para la conducta está planteado entonces en base a fenómenos que provocan las situaciones aversivas o de conflicto. Desde la psicología social, se piensa la angustia y la ansiedad como productos de una falta de coherencia cogniscitiva. Osgood y Tannenbaum 
hablan del principio de simetría basado en la presuposición de que las personas necesitamos y buscamos situaciones en las que todos los elementos sean congruentes entre sí y respecto a nosotros mismos. Festinger utiliza el principio de consonancia. Para él, la ansiedad puede nacer de la disonancia entre el yo y la realidad social (Cf. Tous i Ral, 1996: 121-122).

Al analizar el pensamiento de Albert Camus, Mijaíl Málishev vuelve sobre la estructura primordial de la existencia humana y destaca que el hombre tiene dos actitudes ante el sentido y transcurso de su vida. Puede adoptar una postura de indiferencia o una tendencia a reflexionar profundamente sobre su existencia, con gran dosis de angustia, a tenor de la situación del ser humano en el mundo. ${ }^{9}$

Estas dos posturas -en apariencia antagónicas pero a veces complementarias- del ser humano ante su propia vida se verifican en En vida de Haroldo Conti. La tensión entre la indiferencia -la vida inauténtica heideggeriana, sin aparente preocupación por cuestiones trascendentales- y la visión angustiosa de la realidad bonaerense está presente en los protagonistas de la novela. Los diferentes aspectos del hombre moderno ante la sociedad en la que vive se congregan en el personaje principal y en el resto de los personajes. Oreste vive en lo más hondo de su ser el carácter tedioso de la vida en Buenos Aires. Para Rita Gnutzmann, "Si por un lado Oreste es un personaje concreto, frustrado, en plena "midlife crisis", por otro es símbolo del hombre en general, confrontado con una existencia sin sentido" (Gnutzmann, 1990: 103).

El carácter tedioso de su vida explica la visión desgarradora de los personajes de la novela. La mayoría de ellos aparecen descritos como "sacos de tristeza", como el gordo de los espolvoreadores que "resoplaba como un toro en celos" en su "mierda de oficina" (114-115). La situación de estos personajes es tanto más patética cuanto que, cuando se reúnen, no mantienen conversaciones. No charlan; tan sólo hablan, cada uno desde su soledad ${ }^{10}$. Consciente de su propia soledad en la ciudad, el protagonista principal, Oreste, también tiene conciencia de la soledad del resto de los personajes, sobre todo los que lo rodean, en el presente como en el pasado. A través de la suya propia, parece cargar con la de ellos (56-57). Hasta cuando está acompañado, Oreste se siente solo y como encerrado en medio de una Buenos Aires que es, según Conti, un conglomerado de soledades. La imagen del protagonista en el autobús 33, donde se ve empujado y "amasijado entre un gordo [...] y un tipo sentado en el último asiento que por lo visto tenía rodillas de acero" (205), traduce muy bien su

${ }^{9}$ Según él, "Comúnmente, el hombre vive sin pensar mucho en el sentido de su existencia, ya que el ritmo exterior de la vida habitual le impone sus normas de juicio y de valor. Sin embargo, de vez en cuando, le alcanza la angustia, la tristeza o el aburrimiento; se lamenta de que la realidad ha perdido su sentido, y que su vida le parece insípida y monótona." (Cf. Málishev, 2000-2001: 235).

${ }^{10}$ El narrador dice lo siguiente: "Roque habla del corazón puro y la sencilla intención. Parece el Kempis. Los demás hablan también. Hablan todos. El propio Juan habla una vez.” (18). 
sentimiento de arrinconamiento y encierro en un universo que mira con esa "lenta extrañeza de las mismas cosas" (172), un universo ajeno.

Además, es interesante subrayar también ese "sabor amargo en la boca" que le agarrota el cuerpo en un pasaje de la novela (178). Materializa su amargura ante su trágica situación en la ciudad. Está amargado y asqueado por su vida, por la ciudad y por los hombres. Todo se le antoja porquería y podredumbre (64). Del mismo modo, el vómito de Oreste, quien se siente "tan solo, tan Buenos Aires y tan de noche" tras escuchar los proyectos de sus amigos Carlitos Linari y Lalo Campi (152-153), puede interpretarse como una manifestación tajante de ese sentimiento de asco que le tiene a la ciudad y a la vida que en ella lleva, de la náusea -esa es la palabra- permanente que le provocan el tedio, la soledad y el alboroto. Esta actitud es muy característica del melancólico endógeno-depresivo tal como lo describe Viktor Frank1. ${ }^{11}$

Fuera del paraíso que para él es el universo familiar y los polvorientos e interminables caminos del pueblo, Oreste tiene que lidiar con la angustia de estar arrojado trágicamente a Buenos Aires, "al mundo, a los puestos de salchichas, los quioscos de revistas, las caras de mufa, la legión de tipos nunca repetidos que cruzaban sus destinos fugazmente en una hora cualquiera" (158). No se siente identificado con lo que, según el irónico narrador, algunos llaman "nuestro estilo de vida" (161). Es que, para Oreste, la felicidad se encuentra en un mundo pretérito, cuando todavía erraba por las calles de su pueblo, entre los suyos, o cuando todavía estaba lleno de proyectos y enamorado de Luisa, es decir, "Cuando uno la tiene delante no la ve." (52)

Para Gaetan Picon, el sentimiento del absurdo nace del conflicto entre nuestra exigencia de una vida válida dentro de un universo racional y la realidad objetiva de un mundo y una vida que no se pliegan a esa exigencia (Picón, 1976: 124). Pues, el darse cuenta de su gran pérdida y de la profundidad del vacío que lo rodea exacerba la angustia de un Oreste caracterizado por la desgana, la falta de entusiasmo por una vida tediosa, una vida en la que no se reconoce, en fin, una vida absurda. Dicha angustia existencial lo lleva muchas veces a hacerse preguntas. Su cabeza se transforma así en "un amasijo de preguntas" sobre ese mundo suyo en el que "se mezclan Luisa, un gato vagabundo, Mandrake, un dolor de muelas, la Pequeña Lulú, y el propio Oreste" (58).

Atenazado por la ansiedad a consecuencia de una "amenazante pérdida de sostén en el mundo" (Längle, 2005: 57), Oreste se mueve por la ciudad como un fantasma, levitando y flotando como un globo, un montón de trapos, o simplemente como una bola líquida:

${ }^{11}$ Según este psicoanalista, "La desvaloración, no sólo de sí mismo, sino del universo entero, crea en el melancólico una misantropía general. Se siente asqueado de sí mismo, y también de los otros. Ningún valor prevalece a sus ojos." (Frankl, 2001: 294). 
Girando y golpeando blandamente como un tronco a la deriva dobló por Perú llevado por la corriente ya que a esa altura había olvidado la cita con Silvia. Su cabeza, porque su cuerpo era un exhausto montón de trapos, flotaba en medio de la gente igual que una mancha de aceite.

Una bola líquida que reemplaza a su cuerpo revienta debajo de su cabeza en cámara lenta y Oreste zozobra entre humores y transparencias vagamente marítimas. (50)

A tenor de lo que acabamos de ver sobre la intensidad de la angustia del protagonista, podemos decir que ésta es de tipo neurótico, puesto que, en opinión de Frankl, la "sensación de flotar en el aire" es muy característica del individuo aquejado de angustia neurótica (Frank1, 2001: 242), en tanto que se siente sin suelo en que apoyarse. Oreste no se identifica con las normas de la sociedad; no se identifica con sus instituciones, como el sistema bancario o la Iglesia. Es lo que explica la visión crítica en esta novela de la institución bancaria y del sistema económico encarnado por la severa mirada del rostro de San Martín en el billete de cien pesos (106). El Banco Hipotecario aparece pintado como un panteón donde empleados fríos y distantes entierran los ahorros, la economía, las aspiraciones y la dignidad de la gente a la que tratan desdeñosamente como meros números (106-107).

Volviendo a la desgarradora situación de nuestro protagonista, hay que añadir que En vida presenta numerosos pasajes en los que Oreste, absorto en sus recuerdos, nota cómo llega a alcanzar un hibridismo que le hace sentirse tan sólo como una idea, una especie de noción, de vaga sombra entre dos tiempos. Por esta razón, no parece estar convencido de que su propia historia, ese "puñadito de gestos y manoteos, ropas, alegrías y zozobras" (206), merece ser contada; y se apropia de las historias de otros. El sentimiento de enajenación lo lleva incluso a dudar de su propia identidad, al igual que de la de Requena. ${ }^{12}$

\section{LA EXISTENCIA INAUTÉNTICA}

Para Erich Fromm, el industrialismo moderno ha tenido éxito en la producción de autómatas, de hombres enajenados cuyas fuerzas y acciones se han convertido en algo ajeno, algo que no depende de ellos sino del sistema (Fromm, 1981: 10). Los rasgos característicos, los denominadores comunes de los personajes de En vida son, precisamente, la enajenación, la marginalidad y la miseria, tanto material como emocional. Gerardo Mario Goloboff habla, refiriéndose a la narrativa contiana, de la puesta en escena de "desclasados, vagabundos, abúlicos. Desapropiados, verda-

${ }^{12}$ Dice el narrador: "Cuando pensaba en la vida pensaba en ese otro Requena y mientras pensaba de esa manera seguramente él mismo era otro Oreste. Para ellos, el sonido de la trompeta." (152) 
deros "desconocidos"“, incluso para sí mismos (Goloboff, 1972-1973: 7). Los que peor caracterización parecen tener son los personajes segundarios. Llevan una vida marcada por lo que los existencialistas llaman el absurdo. Según la ontología heideggeriana, el absurdo está basado en la existencia inauténtica, en la adopción de una vida que reduce las posibilidades del individuo a las banalidades del presente, a la caída en la estupidez, la mediocridad y la decadencia de la sociedad moderna.

Los "amigos" de Oreste son seres grotescos y absurdos que sufren lo que Vattimo llama la "enfermedad de las cadenas" (Vattimo, 2003: 289). Intentan dar una impresión de felicidad cuando en realidad son profundamente infelices. Cuando se reúnen en el bar de Pino, cantan, bailan y aplauden pese a que no hay "alegría en ninguno de ellos" (150). Sus canciones son el reflejo de su desnuda tristeza. ${ }^{13}$ Pasan los fines de semana entre borracheras, prostitutas y peleas absurdas, como la que protagonizan en el club Centenario (143-144). Los mueven instintos primarios. Están obsesionados por los goces sexuales y la efímera satisfacción de sus deseos. La sexualidad se convierte para ellos en lo que Viktor Frankl llama un "medio de gozar", es decir, un simple medio para alcanzar el placer (Frankl, 2001: 224). Citemos, por ejemplo, el tórrido acto sexual que Oreste realiza con la hasta entonces desconocida secretaria del señor Borsani (167-170) o la excitación que le produce la vecina del cuarto piso (159). Lo mismo le pasa a Requena, con sus revistas pornográficas, a Paco, Corvalán y el resto, con las prostitutas. A este respecto, hemos de subrayar que, si las prostitutas pueden verse como un signo de libertad en tanto en cuanto que representan la posibilidad de satisfacción del deseo carnal sin sentir las ataduras de una relación amorosa sujeta a condicionamientos y exigencias, la atracción por ellas no hace más que poner al descubierto la vacuidad de la existencia de los personajes. Pues, los hombres que se repliegan en lo puramente sexual sufren de una alteración del proceso de madurez psicosexual, dice Frankl; y

La enorme cantidad de placeres sexuales y de mujeres que acumulan en su historia no impide que su vida sea, en el fondo, vacía. Su mundo es más vacuo que el de quien ama de verdad, y su vida constituye un amargo fracaso. (Frankl, 2001: 226)

Roque es un fracasado, un ser enajenado, un marginal que vive en el séptimo piso de una pensión cuyo ascensor no funciona y en un cuarto miserable que le cuesta la mitad de su no menos miserable sueldo. Su enajenación se patentiza todavía más con la irónica evocación de su movilidad laboral, de la cantidad de direcciones en las que ha trabajado como pequeño funcionario, teniendo el destino en manos de otros que deciden por y para él sin consultarle (15). A pesar de vivir en medio de

${ }^{13}$ Según el narrador, "Oreste hubiera querido cantar con los otros, pero la tristeza era de Corvalán y de Paco y del tipo del mostrador.” (130) 
una ciudad caracterizada por el gentío, el ajetreo y el tumulto, Roque está completamente solo. Por esta razón, despierta en Oreste un sentimiento de lástima. Está vencido por el pesimismo, la falta de perspectivas, el desaliento, la frustración, la impotencia, la desazón. Se siente condenado, sin escapatoria, a la infelicidad y la soledad, y no tiene ánimos para cambiar nada. Pues, "no hay nada en este podrido mundo que le pueda hacer levantar la cabeza", advierte el narrador (19).

$\mathrm{Si}$ Roque es un tipo con una prolijidad verbal, un personaje al que le gusta hablar, filosofar, encadenar una tras otra sus pensamientos y quejas sobre la condición humana, en general, y la suya, en particular, Juan es, al contrario, un ser poco propenso al habla; es un hombre taciturno. Las pocas veces que habla lo hace, como verdadero marinero fracasado, sobre los barcos. Su universo no va más allá del mundo de la navegación. Está "institucionalizado"

En lo que a Paco se refiere, hemos de decir que es el típico ser inauténtico. Se empeña, pese a sus limitados medios económicos, en incorporarse en la sociedad consumista. Le gusta aparentar, dar la sensación de felicidad. Una felicidad que sólo ve en el tener, en la riqueza material. ${ }^{14}$ Estos aires y sueños de grandeza hacen de él un personaje ridículo, casi esperpéntico, y demuestran la profundidad de su enajenación:

[Oreste] Recomponía su cara de perpetuo asombro asomándose entre nubes de alcohol, como se dice, lo cual es bastante exacto porque era la nube de él y la de Paco, evidentemente más grande, para preguntarle si le pasaba algo, que es lo que preguntaba Paco en todo momento venga o no al caso. Sigue el viaje por la Chevrolet 47 [de Paco] con escape abierto. Paco habla a los gritos de alguna mina o de la casita que le gustaría tener en Domselaar (es la única precisión de su vida aunque cambia de lugar cada vez que habla de la casita, que no son pocas) porque está harto de esa existencia (dice existencia para hablar fino), de esa existencia de mierda que Oreste no sabe ni siquiera en qué consiste. (12)

Está tan ridículamente inmerso en el sistema productivo capitalista que no tiene personalidad propia, convertido en máquina de vender, enajenado sin tiempo siquiera para sí mismo, siempre preocupado por los puntos, los pedidos, las estadísticas y los manuales de marketing. ${ }^{15}$

${ }^{14}$ Fromm se lamenta de que el carácter del hombre del siglo XX "se orienta más hacia una pasividad considerable y una identificación con los valores de mercado. El hombre contemporáneo es ciertamente pasivo en gran parte de sus momentos de ocio. Es el consumidor eterno; se "traga" bebidas, alimentos, cigarrillos, conferencias, cuadros, libros, películas; consume todo, engulle todo. El mundo no es más que un enorme objeto para su apetito: una gran mamadera, una gran manzana, un pecho opulento. El hombre se ha convertido en lactante, eternamente expectante y eternamente frustrado." (Fromm, 1981: 8)

${ }^{15}$ Para Fromm, el hombre moderno "se ha transformado a sí mismo en un bien de consumo, y siente su vida como un capital que debe ser invertido provechosamente; si lo logra, 
Como Paco, Requena, el compañero de oficina de Oreste es, según el narrador, otro "completo hijo de puta" (40) entregado a la vida mecanizada y regida por ideas preestablecidas. Se obstina en sus esfuerzos por triunfar en un sistema productivo competitivo en el que el tener parece determinar el ser. Alberga el sueño de una mejoría de su situación laboral y financiera, está obsesionado por la grandeza y el progreso tal como lo concibe la sociedad consumista moderna (41).

Detrás de la actitud de Requena y Paco se esconde una estrategia de ocultación de la vacuidad de su existencia. Ante sus insuficiencias, optan por perderse en la masa, por perder "su cualidad más propia y peculiar: la responsabilidad" (Frankl, 2001: 126). Huyen hacia la masa para, a través de este proceso de enmascaramiento, ocultar la verdadera desnudez de su condición de seres fracasados y la marcada tensión entre su yo y su ideal de yo. Pues, para Gianni Vattimo, en el hombre moderno, "el disfraz es asumido para combatir un estado de temor y de debilidad" (Vattimo, 2003: 31). A este mecanismo, que los psicólogos llaman evitación, obedece su forma ostentosa de actuar, que añade un toque de grotesco a su personalidad. A Paco, por ejemplo, le da satisfacción hacerse notar cuando entra en los locales de ocio de la costa. Lo hace con los acelerones de su Chevrolet 47 y lo intenta hacer con el musicante en el club Centenario (136). De la misma manera, detrás de la aparente vitalidad y gracia de Corvalán, el amigo de Paco, con su amplio repertorio de chistes, se esconde una profunda tristeza ${ }^{16}$. Según el narrador, Corvalán tiene una voz parecida a la del padre de Oreste, "una voz grande y triste" (129-130). Inauténtica es también la vida de Monteverde, el otro compañero de Oficina de Oreste. Pues, todavía no ha tomado conciencia de lo trágica que es su vida caracterizada por la infelicidad, la soledad y la marginación. Irónicamente, dice el narrador, tiene "un pie en la tumba y no se calienta" (45). El hecho de que el gordo Sixto "no duerme porque piensa que cualquier día de estos se muere" (20) no hace más que reforzar nuestra visión como absurda de la condición de esos hombres, que no tienen nada que perder en un mundo que no parece hecho para ellos, pero que le tienen gran aprecio a la vida.

habrá "triunfado" y su vida tendrá sentido; de lo contrario será "fracasado". Su "valor" reside en el precio que puede obtener por sus servicios, no en sus cualidades de amor y razón ni en su capacidad artística. De allí que el sentido que tiene de su propio valor dependa de factores externos y que sentirse triunfador esté sujeto al juicio de otros. De allí que viva pendiente de estos otros, y que su seguridad resida en la conformidad, en no apartarse nunca más de los pasos del rebaño." (Fromm, 1981: 8-9)

${ }^{16}$ Según David Viscott, es posible disfrazar, negar o racionalizar los sentimientos, "pero el sentimiento doloroso no desaparece hasta que ha recorrido su curso natural. En realidad, cuando eludimos un sentimiento, sus efectos dolorosos suelen prolongarse y resulta cada vez más difícil dominarlo" (Viscott, 1991: 18). Es quizá lo que explica la tristeza interior de estos personajes. 


\section{LA BÚSQUEDA DE AUTENTICIDAD}

Si Requena y Paco parecen haber optado, como lo hemos señalado, por esa actitud de mala fe que consiste en evitar fijarse en la fealdad de la realidad que los rodea, en inscribirse en el fariseísmo y las actitudes prehechas de la comedia humana, Oreste es un personaje que puede catalogarse como inconformista en ya que rechaza y desdeña todo lo establecido. La angustia y la náusea que supone el encuentro con la ruinas son, según afirma Lamana, la condición necesaria para que queramos alejarnos de ellas (Lamana, 1967: 23). No es de extrañar, entonces, que sea este protagonista el portador de la idea de libertad. Es más: la elección de su nombre (Oreste) no es gratuita. Este personaje mítico, símbolo de la revolución libertaria, lo encontramos también en Les mouches de Jean-Paul Sartre donde lo vemos rebelarse contra Júpiter y proclamar su libertad ${ }^{17}$. En otro momento, dice que "la vie humaine commence de l'autre côté du désespoir" (Sartre, 2000: 238).

La desesperación causada por su situación en Buenos Aires es entonces un condicionante para que Oreste sienta la necesidad de escapar del tedio. También, hay que señalar que esta actitud nuestro protagonista la debe a las enseñanzas que le inculcó su padre desde niño. Oreste es hijo de un vagabundo, hijo de un hombre para quien la libertad es una condición primordial para alcanzar la plenitud, una necesidad para el ser humano. Recuerda el narrador en una analepsis:

Su padre se vuelve y lo mira pensativamente. "Oreste, no he sido gran cosa como padre. Hay que admitirlo. Pero quiero que entiendas esto al menos. Somos aves de paso. No levantes una casa demasiado sólida ni te llenes de cosas. Te basta con un par de alas, muchacho." (45)

Esta profunda reflexión del padre sobre la metafísica de la finitud del ser humano y la concepción de éste como ave de paso en un mundo considerado como mero espacio de tránsito puede verse como una posible explicación de la diferencia entre la actitud de Oreste y la de Paco o Requena, quienes se esfuerzan, de manera más o menos consciente, por disfrazarse, por representar un papel, por amurallarse detrás de una fachada artificial ante el mundo.

La ansiedad de Oreste es tanto más intensa cuanto que, al contrario de sus amigos, sabe que está viviendo una realidad que no le corresponde. Por esta razón, "sueña con cambiar de piel e irse a la aventura, a vagar por el mundo" (Redondo, 2004: 89). Es que, para él, lo último que debe olvidar un hombre es cómo ser un vagabundo. Sustenta esta reflexión en su convicción de que el hombre nació vagabundo. Antepone el aprendizaje por el vagabundeo al aprendizaje por la institución

${ }^{17}$ Dice Oreste: “Je ne suis ni le maître ni l'esclave, Jupiter. Je suis ma liberté! A peine m'as -tu créé que j'ai cessé de t'appartenir.” (Sartre, 2000: 235). 
escolar de cuya pertinencia reniega. Es lo que explica la debilidad que tiene hacia los barcos. El barco reviste en él un carácter simbólico positivo. Representa la posibilidad de cumplimiento de la realización del yo, de la liberación de las tinieblas embrutecedoras de una ciudad asfixiante, y la posibilidad de un mundo mejor simbolizado por la luz que sólo él parece advertir en la neblinosa ciudad (68). En esta novela, como en todas las narraciones de Conti, el allá es siempre el espacio del deseo, el espacio deseado y prometedor de una mejoría de las condiciones del aquí. La visión del pailebote en San Fernando constituye el detonante de su realización de la necesidad de marcar una ruptura, una invitación a salvar las barreras de la alienación y de la vida desgarradora, a librarse y liberarse de las cadenas de la soledad para él tan bonaerense. Este momento clave para la evolución psicológica de Oreste es recordado de la siguiente manera:

Una o dos veces había estado a punto de oír ese sonido. Aquella tarde en un varadero de San Fernando. No recordaba cómo había ido a parar allí. Vio en un rincón la figura herrumbrosa de un viejo pailebote. $\mathrm{Y}$ aquello, vaya a saber por qué, la luz, la tarde y ese maltrecho y abollado esplendor pareció recordarle algo que había olvidado hasta ahora y que, con todo, era absolutamente primordial. Por lo menos entendió que hasta entonces había estado perdiendo el tiempo o que estuvo caminando a ciegas todos esos años, la vida. Y fue así que levantó la cabeza y aspiró el aire frío de la tarde y en el momento que esa gran verdad estaba por entrar en él, una voz o la bocina del tren o el mero perfil de una nube le hizo olvidar todo, antes de recordarlo. (152)

Subrayemos, sin embargo, que, aunque el protagonista de En vida siempre ha pensado en irse de la ciudad algún día, es a partir del encuentro con Margarita y su estancia en la casita de madera de la prostituta cuando empieza a preguntarse por qué sigue en Buenos Aires. Es a partir de este momento cuando tiene plena conciencia de la necesidad imperiosa, de la obligatoriedad para él, de exiliarse. Así lo cuenta el narrador: “... pensó por primera vez entera y completamente y preguntó qué hacía allí, en medio de toda esa gente, mientras existía ese hueco perdido en la mañana..." (36)

El protagonista anhela un viaje hacia lo primitivo, sueña con la vuelta a una vida en contacto con la naturaleza, lejos de la civilización moderna que no hace más que embrutecer al ser humano. Pues, piensa en esas tierras cuando, planeando las vacaciones con su familia, le llega el turno de decir adónde le gustaría ir:

Oreste, que ha esperado su oportunidad, saca a relucir aquel viejo paisaje que había recortado del Life. Entre lentos sorbos de vino y complacido de su voz recorre una vez más aquella reluciente playa de las Samoa o Fénix o Manihiki, saluda con una inclinación de cabeza al grupito de nativos, a la izquierda, y luego se encamina resueltamente hacia la choza que asoma por debajo de las palmeras, a la 
derecha, se demora un momento en las sombras de la galería, extiende la mano y empuja la puerta roja... (162)

Interesa destacar el momento muy freudiano en el que Oreste sueña que está en una de esas islas con playa de arena blanca y casa con techo de paja, en compañía de su padre y del gordo Primo (177-178). También es significativo ese otro sueño que hace en las dependencias del Banco Hipotecario donde se pone de manifiesto su desgarro existencial en contraposición con la omnipresencia, en las islas, de la luz, sinónimo de plenitud (107). No es exagerado ver en estas recurrentes ensoñaciones señales de lo que Freud llama "sueños de angustia" (Freud, 1985: 606 y ss.) en la medida en que traducen las obsesiones de Oreste aquejado, como decíamos, de una neurosis existencial, de una falta de adecuación de su yo con su ideal de yo. Los sueños del protagonista son la manifestación del resurgimiento en los momentos de reposo de sus deseos reprimidos. Siente que algo en su interior lo llama a la aventura, pero no se atreve a dar el paso, a tomar su destino en mano. Desde este punto de vista, Oreste representa al típico individuo moderno que, según Fromm, tiene miedo a la libertad y busca "caminos para rehuirla" (Fromm, 1978: 29). El narrador sintetiza sus vacilaciones de una manera bastante gráfica:

La luz volvió a cambiar y sin embargo Oreste no se movió de donde estaba. La gente corría hacia su destino sin desviarse una pulgada. Él, en cambio, sintió que podía cruzar la calle o no, que podía torcer a un lado u otro, que podía o no volver a su casa.

Oreste vuelve a su casa. (183)

Una decisión que finalmente tomará el protagonista, dándole la espalda a su casa y su familia, aunque intenta regresar en una ocasión, tras semanas de ausencia. Pero, cuando se acerca a la puerta y ve entrar a su hija Susana, da media vuelta y se aleja de la casa. Oreste se acobarda ante la idea de tener que afrontar la mirada de sus hijos, de tener que darles explicaciones. Por esta razón, suplica a Margarita que le diga a Marcelo, quien había salido a buscarlo, que no sabe nada de él. A pesar de esta actitud de cobardía, está convencido de haber tomado una decisión justa cuanto más que es la expresión de su libertad, un acto de rebeldía por el que rompe con su pasado y con lo que Georg Simmel llama el "imperativo categórico" (Simmel, 2003: 86-91). Una convicción que le lleva a opinar que su hijo lo entenderá como él, en su día, entendió que su padre se marchara de casa a bordo del Morris Cowley modelo 26 del tío Ernesto, otro vagabundo (190-191). Dice el narrador que Oreste piensa que Marcelo “Tal vez un día, cuando a su hora él también recuperara los fantasmas y las sombras, terminase por reconocer este paisaje y al hombre que acaso por primera vez había escogido algo en la vida." (213)

Además, con esta actitud Oreste tipifica el comportamiento de una personalidad neurótica en relación con sus amantes: atracción y repulsión, amor y odio al mismo 
tiempo (cf. Freud, 1981: 199-200). En el rechazo a Luisa y la atracción por Margarita hay un trasfondo relacionado con la angustia que sufre por la ausencia de la casa familiar y de su madre. Él mismo ve en la imagen de Margarita en su casona la figura de su madre en el pasillo del hogar familiar en el pueblo. Al mismo tiempo que sustituye a la madre, Margarita también sustituye a su mujer y a sus hijos. ${ }^{18}$ Ella, a su vez, ve en Oreste la figura de su padre. Se establece entonces entre estos dos personajes una especie de doble relación edípica que ataca simbólicamente los cimientos de la moral social.

Conviene decir también que es muy significativo el que el terraplén que alberga la casa de Margarita sea donde Oreste empieza a ver las cosas de otra manera. Los vecinos de la prostituta son para él otra gente, aunque no sabe dónde está la diferencia $^{19}$. Eso quizá se explique por que ve en esta casa la actualización del hogar de la infancia. A través de ella, se transporta al universo familiar, al pueblo que representa para él el paraíso perdido, su verdadera obsesión. El ingreso en la casa puede verse como la vuelta al antro materno, a la protección, de un Oreste anheloso de un refugio, de un arca de $\mathrm{Noe}^{20}$ donde pueda resguardarse del gran diluvio que representa la ciudad.

El que Oreste decida pintar las paredes de la casita de color damasco y la puerta de rojo, como la choza de su imaginaria isla, participa de su intención de hacer de este lugar su isla de libertad, aunque no renuncia a su viaje. Desde este punto de vista, podemos afirmar que la casa de la prostituta es también un sustituto, una especie de máscara de la isla soñada. Por lo cual, se puede pensar que es un mero espacio transitorio ya que, si bien el protagonista tiene cumplido uno de sus objetivos -es decir, salir de la cuidad -, el otro, el del viaje, sigue intacto. Le falta echarse al camino abierto por su padre o por Paco, quién se marcha a Río Grande al darse cuenta de haber estado equivocado toda su vida. Pero, siente en lo más hondo de su ser lo que los psicólogos llaman una herida narcisista, al experimentar la imposibilidad de satisfacer su deseo de ser-más-ser y al verse incapaz de escapar de la angustia de ser-en-el-tiempo (Potestad y Zuazu, 2007: 160).

Para concluir, hay que dejar claro que el desarraigo existencial del protagonista no es fruto de una exclusión, de un rechazo que la sociedad ejerce sobre él. Al contrario, es consecuencia de su no identificación con todo el sistema económico, so-

${ }^{18}$ El comportamiento de Oreste tiene su parangón en La vida breve de Juan Carlos Onetti, donde Brausen abandona a su mujer y "se trueca, de repente, en el amante de una prostituta" (Arroyo, 1980: 268).

19 "También los tipos de la tele ahora parecen distintos", dice el narrador (195).

${ }^{20}$ Señalemos que la imagen de la casa de Margarita, crujiente y espaciosa, que se sacude como una barcaza a cada paso de tren, es bastante significativa para Eduardo Romano y justifica esta metáfora del arca (Romano, 1976: 17). 
cial y cultural. En vida ofrece muchos guiños contra el modelo de vida imperante. La de Oreste es la historia de un hombre rebelde que repudia todos los elementos constitutivos de los cimientos de la moral conservadora, y que está en una perpetua búsqueda de una identidad propia. ${ }^{21}$ Es la de un hombre que quiere exteriorizar un combate interior, concretizar o consumar ese divorcio con la sociedad capitalista y la moral católica; ese divorcio que lleva arrastrando desde la infancia o que, quizás, le viene de herencia. Así es cómo hay que entender el que Oreste abandone trabajo, casa, familia y, por consiguiente, sus prerrogativas de padre y marido para trasladarse a vivir en la costa con la prostituta Margarita, dejando libre paso a la libertad, al egoísmo y al goce individualista.

\section{BIBLIOGRAFÍA}

ARroYo, Anita.

1980 Narrativa hispanoamericana actual (América y sus problemas). Puerto Rico: Editorial Universitaria.

CONTI, Haroldo.

1971 En vida. Barcelona: Barral Editores.

FONTÁN-JUBERO, Pedro.

1991 Los existencialismos: claves para su comprensión. Madrid: Cincel. FRANKL, Viktor.

2001 Psicoanálisis y existencialismo. De la psicoterapia a la logoterapia. México: FCE.

FREUD, Sigmund.

1981 Paranoia y neurosis obsesiva. Madrid: Alianza Editorial.

1985 La interpretación de los sueños. Barcelona: Planeta-De Agostini. FRÖHLICH, Werner D.

1986 La angustia. Madrid: Alhambra.

FROMM, Erich.

[1956] Psicoanálisis de la sociedad contemporánea. México-Buenos Aires: FCE.

1978 El miedo a la libertad. Buenos Aires: Paidós.

1981 La condición humana actual. Barcelona: Paidós.

FULLAT, Octavi.

2002 El siglo postmoderno (1900-2001). Barcelona: Editorial Crítica.

${ }^{21}$ Según Fromm, la búsqueda de un sentimiento de identidad es "tan vital e imperativa, que el hombre no podría estar sano si no encontrara algún modo de satisfacerla." (Fromm, [1956]: 57) 
GNTUZMANN, Rita.

1990 "Haroldo Conti: de la soledad a la solidaridad", Cuadernos para la investigación de la literatura hispánica, n 13, pp. 99-106.

GolobofF, Gerardo Mario.

1973 "Haroldo Conti y el padecimiento de la máscara", Nuevos Aires, $\mathrm{n}^{\circ}$ 9, dic. 1972/enero-febrero 1973, pp. 3-13.

HEIDEGGER, Martin.

1996 El ser y el tiempo. Madrid: FCE.

JOLIVET, Régis.

1970 Las doctrinas existencialistas. Madrid: Gredos.

LAMANA, Manuel.

1967 Existencialismo y literatura. Buenos Aires: Centro Editor de América Latina.

LÄNGLE, Alfried.

2005 "La búsqueda de Sostén. Análisis Existencial de la Angustia", Terapia Psicológica, vol. 23, n 2, pp. 57-64.

LUKACS, Georg.

1966 Sociología de la literatura. Madrid: Península.

MÁLISHEV, Mijaíl.

2001 "Albert Camus: de la conciencia de lo absurdo a la rebelión", Ciencia Ergo Sum, vol. 7, no 3, noviembre 2000-febrero 2001, pp. 235245.

Mingorance, Antonio F.

1996 "La filosofía de la existencia en la Argentina", en La Argentina y Europa (1930-1950) I. Bahía Blanca: Universidad nacional del Sur, pp. 181-189.

PICON, Gaëtan.

1976 Panorama de la nouvelle littérature française. Paris : Gallimard.

Potestad, Fabricio de y Ana Isabel ZUAZU.

2007 Conciencia, libertad y alienación. Bilbao: Editorial Desclée Brouwer.

REDONDO, Nilda S.

2004 Haroldo Conti y el PRT: arte y subversión. Buenos Aires: Ediciones Amerindia.

ROMANO, Eduardo.

1976 "Estudio preliminar", en Cuentos y relatos de Haroldo Conti. Buenos Aires: Editorial Kapelusz.

ROMERO, José Luis.

1965 El desarrollo de las ideas en la sociedad argentina del siglo XX. México-Buenos Aires: FCE.

SARTRE, Jean-Paul.

1999 El existencialismo es un humanismo. Barcelona: Edhasa. 
2000 Huis clos suivi de Les mouches. Paris : Gallimard.

SIMMEL, Georg.

2003 La ley individual y otros escritos. Barcelona: Paidós.

SPERONI, Marta y Abel POSADA:

2000 "Las víctimas de la espera", en Haroldo Conti. Sudeste-Ligados. Madrid: Galaxia Guttenberg-Círculo de Lectores, pp. 534-571.

TOUS I RAL, Josep $\mathrm{M}^{\mathrm{a}}$.

1996 Psicología de la personalidad. Diferencias individuales: biológicas y cognitivas en el procesamiento de la información. Barcelona: EUB.

VATTIMO, Gianni.

2003 El sujeto y la máscara. Nietzsche y el problema de la liberación. Barcelona: Ediciones Península.

VISCOTT, David.

1991 El lenguaje de los sentimientos. Barcelona: Círculo de los Lectores. 